\title{
CARACTERIZAÇÃO MECÂNICA E MICROESTRUTURAL DE UM AÇO INOXIDÁVEL MARTENSÍTICO DE MÉDIO TEOR DE CARBONO APÓS TÊMPERA E REVENIMENTO*
}

\author{
Paulo Augusto Cota Leite 1 \\ Nayara Aparecida Neres da Silva ${ }^{2}$ \\ Wellington Lopes ${ }^{3}$ \\ Elaine Carballo Siqueira Corrêa ${ }^{4}$
}

\section{Resumo}

Os aços inoxidáveis martensíticos, em geral, aliam boas propriedades mecânicas e satisfatória resistência à corrosão, características associadas à possibilidade de realização de tratamentos térmicos de têmpera e revenimento. Nesse contexto, no presente trabalho foram avaliados os efeitos das condições desses tratamentos na microestrutura e nas propriedades mecânicas de um aço inoxidável martensítico de médio teor de carbono. Foram consideradas três temperaturas de aquecimento na têmpera e seis temperaturas de revenimento. A avaliação microestrutural foi realizada por meio de microscopia óptica e microscopia eletrônica de varredura. As propriedades mecânicas foram avaliadas por meio de ensaios de dureza. Foi observada a elevação na dureza do aço com o aumento da temperatura de aquecimento na têmpera, assim como a dissolução dos carbonetos presentes no material. No revenimento subsequente observou-se o aparecimento do pico de dureza referente ao endurecimento secundário a uma temperatura de $500^{\circ} \mathrm{C}$.

Palavras-chave: Aço inoxidável martensítico; Têmpera; Carbonetos.

\section{MECHANICAL AND MICROSTRUCTURAL CHARACTERIZATION OF A MARTENSITIC STAINLESS STEEL WITH MEDIUM CARBON CONTENT AFTER QUENCHING AND TEMPERING}

\begin{abstract}
Martensitic stainless steels present good mechanical properties and corrosion resistance, characteristics obtained through quenching and tempering heat treatments. In this study, the effects of different conditions of quenching and tempering in the microestructure and the mechanical properties of a martensitic stainless steel with medium carbon content were analyzed. The microestructural evaluation was carried out through optical and scanning electron microscopy. The mechanical behavior was carried out by hardness testing. It was observed that the increase in quenching temperature led to higher hardness values, as well as to a smaller content of carbides. Concearning tempering, the ocurrence of secondary hardening was observed at $500^{\circ} \mathrm{C}$ for all previous quenching temperatures.
\end{abstract}

Keywords: Martensitic stainless steel; Quenching, Carbides.

1 Engenheiro de Materiais, Departamento de Engenharia de Materiais, CEFET-MG, Belo Horizonte, Minas Gerais, Brasil.

2 Engenheira Metalurgista, Mestranda, Departamento de Engenharia de Materiais, CEFET-MG, Belo Horizonte, Minas Gerais, Brasil.

3 Engenheiro Mecânico, Doutor, Professor, Departamento de Engenharia de Materiais, CEFET-MG, Belo Horizonte, Minas Gerais, Brasil

4 Engenheira Mecânica, Doutora, Professora, Departamento de Engenharia de Materiais,CEFETMG, Belo Horizonte, Minas Gerais, Brasil. 


\section{INTRODUÇÃO}

Os aços inoxidáveis martensíticos conciliam boas propriedades mecânicas a uma satisfatória resistência à corrosão, além de poderem ser utilizados em baixas e elevadas temperaturas [1,2]. O adequado balanço da composição química garante, além da resistência à corrosão, a ocorrência de transformação austenítica com o aquecimento do material [3]. Dessa forma, para esse grupo de aços inoxidáveis, diferentemente do que é observado para os ferríticos e os austeníticos, as propriedades podem ser alteradas por processamento térmico, ou seja, têmpera e revenimento podem ser conduzidos, produzindo peças com alta resistência mecânica, alta dureza, resistência ao desgaste e ainda alguma tenacidade $[2,4]$. Uma vez que as propriedades dos aços inoxidáveis martensíticos podem ser alteradas de maneira significativa com os tratamentos térmicos, essas ligas são empregadas em uma grande variedade de situações, indo desde vasos de pressão e caldeiras até lâminas de turbinas e ferramentas de corte $[5,6]$.

De acordo com a composição química e a história de processamento, os aços inoxidáveis martensíticos, em uso, exibem estrutura martensítica (revenida) e carbonetos, podendo ainda apresentar ferrita. Nesse contexto, os parâmetros dos tratamentos térmicos de têmpera e revenimento são de fundamental importância para a obtenção do material com desempenho requerido [2].

Diversos trabalhos tem abordado os efeitos das variáveis de processamento térmico na microestrutura e, consequentemente, nas propriedades dos aços inoxidáveis martensíticos, enfocando as análises no desenvolvimento e a evolução de austenita retida/reversa, as possíveis morfologias da martensita e a presença e formação de carbonetos diversos, considerando técnicas distintas de caracterização, como microscopias eletrônicas de varredura e transmissão, difração de raios $x$ e dilatometria, entre outros [1,7,8,9]. Uma ampla compreensão dos fenômenos microestruturais e suas relações com as propriedades em geral é de fundamental importância para as aplicações industriais [8].

Dentro deste contexto, neste trabalho foram investigados os efeitos da temperatura de aquecimento na têmpera e da temperatura de revenimento na microestrutura e na dureza de um aço inoxidável martensítico de médio teor, cuja composição química consiste em 0,45\%C - 0,39\% Si - 14,9\% Cr - 0,65\%Mo-0,10\%V.

\section{MATERIAIS E MÉTODOS}

O material utilizado no trabalho foi um aço inoxidável martensíttico, cuja composição química \% em peso, é mostrada na Tabela 1. O aço foi adquirido na forma de chapas com $2 \mathrm{~mm}$ de espessura.

Tabela 1. Especificação técnica do aço inoxidável martensítico analisado no trabalho

\begin{tabular}{ccccccc} 
Elemento & $\mathrm{C}$ & $\mathrm{Mn}$ & $\mathrm{Si}$ & $\mathrm{Cr}$ & $\mathrm{Mo}$ & $\mathrm{V}$ \\
\hline Teor $(\%)$ & $0,45 \%$ & 0,50 & $0,39 \%$ & $14,9 \%$ & $0,65 \%$ & $0,10 \%$ \\
\hline
\end{tabular}

Os tratamentos térmicos realizados foram a têmpera e o revenimento, conduzidos em um forno da marca Brasimet. Para o tratamento de têmpera, três temperaturas de aquecimento $\left(850^{\circ} \mathrm{C}, 950^{\circ} \mathrm{C}\right.$ e $\left.1050^{\circ} \mathrm{C}\right)$ foram investigadas, com meio de resfriamento em água e tempo de encharque de 30 minutos. No tratamento de revenimento as amostras foram resfriados ao ar, sendo empregadas seis 
temperaturas $\left(100^{\circ} \mathrm{C}, 200^{\circ} \mathrm{C}, 300^{\circ} \mathrm{C}, 400^{\circ} \mathrm{C}, 500^{\circ} \mathrm{C}\right.$ e $\left.600^{\circ} \mathrm{C}\right)$ e tempo de encharque de 30 minutos.

A caracterização microestrutural foi realizada por meio de microscopia óptica (MO) e microscopia eletrônica de varredura (MEV). A preparação das amostras seguir o procedimento metalográfico convencional, envolvendo embutimento a frio, lixamento, polimento com pasta de diamante e ataque químico com Villela $(1 \mathrm{~g}$ de ácido pícrico, $100 \mathrm{ml}$ de álcool etílico e $5 \mathrm{ml}$ de ácido clorídrico) por imersão. Foram empregados o óptico Fortel com sistema de aquisição de imagens Kontrol M713 e o microscópio eletrônico Shimadzu SSX-550.

A análise do comportamento mecânico do aço foi realizada por meio de testes de dureza Vickers (HV) realizados em um microdurômetro HMV Shimadzu modelo 2T, com penetrador Vickers, com carga de $500 \mathrm{gf}$, e tempo de aplicação de 15 segundos. A preparação das amostras para esses testes foi a mesma conduzida para a caracterização microestrutural por microscopia óptica, porém sem a realização de ataque químico.

\section{RESULTADOS E DISCUSSÃO}

\subsection{Caracterização Mecânica e Microestrutural do Material no Estado Inicial}

Na tabela 2 é apresentado o valor médio de dureza do material no estado inicial. Nas figuras 1 e 2 são apresentadas as micrografias obtidas por meio de $\mathrm{MO}$ e do MEV para as amostras no estado inicial.

Tabela 2. Valor de dureza Vickers para a amostra do aço no estado inicial

\begin{tabular}{ll}
\hline & Estado Inicial \\
\hline $\mathrm{HV}$ & $253 \pm 5$ \\
\hline
\end{tabular}

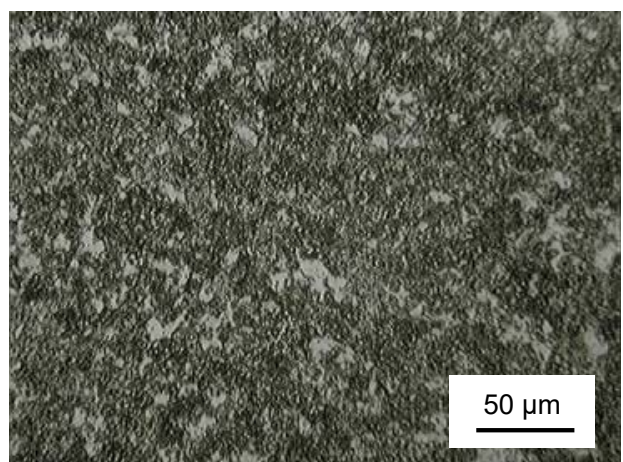

Figura 1. Micrografia (MO) do aço inoxidável martensítico no estado inicial.

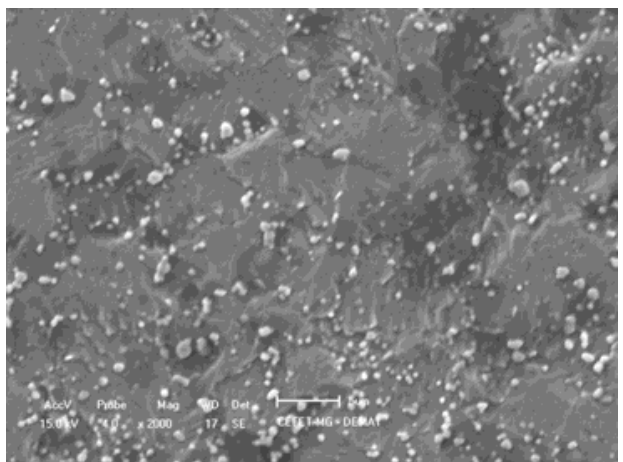

Figura 2. Micrografia (MEV) do aço do aço inoxidável martensítico no estado inicial. 
Por meio da análise das micrografias é possível observar que a microestrutura inicial do aço é composta por carbonetos dispersos em uma matriz ferrítica. Segundo a literatura [10], aços com teor de carbono maior do que $0,2 \%$ e valores de cromo maiores que $12-13 \%$ contêm os seguintes tipos de carboneto: $M_{3} C, M_{7} C_{3}$ e $M_{23} C_{6}$, e a precipitação dos carbonetos presentes vai depender do tempo, sendo que o $M_{3} C$ irá precipitar primeiro, seguido do $\mathrm{M}_{7} \mathrm{C}_{3}$ e por último $\circ \mathrm{M}_{23} \mathrm{C}_{6}$. Neste trabalho, foram identificados apenas carbonetos $\mathrm{M}_{23} \mathrm{C}_{6}$ (Figura 2), caracterizados morfologicamente como pequenos glóbulos isolados, homogeneamente distribuídos na matriz como foi estudado por [11].

\subsection{Caracterização Mecânica e Microestrutural do Material Temperado}

Na tabela 3 são apresentados os valores médios de dureza encontrados para o aço temperado considerando as três temperaturas de aquecimento, representados na figura 3. A elevação da temperatura de austenitização implicou em um aumento na dureza. Esse resultado pode ser associado a uma maior dissolução dos carbonetos de cromo, o que elevam o teor desse elemento e do carbono na matriz austenítica antes do resfriamento [12]. Com isso, é elevada a temperabilidade do material, retardando as transformações difusionais $e$, consequentemente, facilitando a transformação martensítica. Em adição a esse fato, a martensita transformada apresentaria maior teor de carbono.

Tabela 3. Valores de dureza do aço temperado

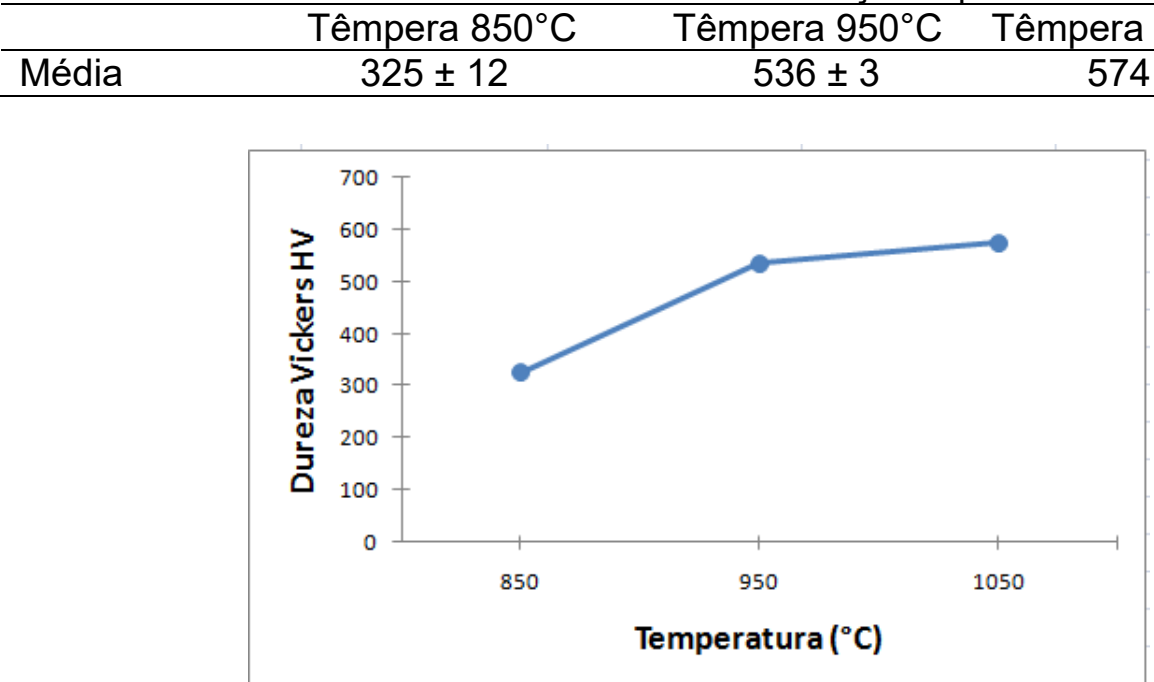

Figura 3. Dureza Vickers em função da temperatura de aquecimento.

Nas figuras 4 e 5 são exibidas as micrografias obtidas por meio de $\mathrm{MO}$ e de MEV do aço inoxidável martensítico temperado a $850^{\circ} \mathrm{C}, 950^{\circ} \mathrm{C}$ e $1050^{\circ} \mathrm{C}$. Por meio da análise por microscopia óptica, verifica-se a presença de martensita nas três condições de tratamento, sendo mais significativa e nítida para a condição de aquecimento a $1050^{\circ} \mathrm{C}$, inclusive em termos de tamanho das plaquetas do constituinte. Por outro lado, as imagens obtidas por MEV possibilitam observar a presença e distribuição de carbonetos no material. Essas imagens mostram a variação na distribuição do carboneto $\mathrm{M}_{23} \mathrm{C}_{6}$ para as três temperaturas de aquecimento empregadas. Observa-se que a quantidade de carbonetos reduziu com a temperatura de aquecimento na têmpera, sendo que para a temperatura de $1050^{\circ} \mathrm{C}$, a presença de precipitados é relativamente discreta. Esses carbonetos 
parecem ser precipitados primários, provenientes de processamentos mecânico metalúgicos anteriores, uma vez que aparecem no material no estado inicial, não tendo sido dissolvidos durante a austenitização, conforme verificado anteriormente [13]. Esses resultados estão de acordo com o que foi observado na avaliação da dureza do material, corroborando a discussão apresentada.
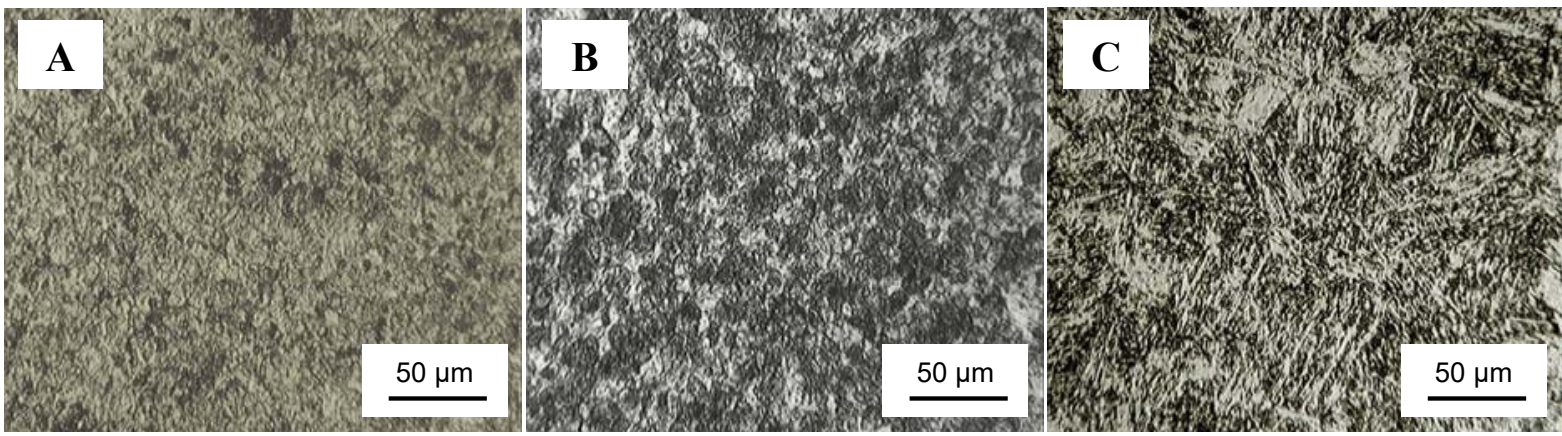

Figura 4. Micrografias (MO) após têmpera a $850^{\circ} \mathrm{C}(\mathrm{A}), 950^{\circ} \mathrm{C}(\mathrm{B})$ e $1050^{\circ} \mathrm{C}(\mathrm{C})$
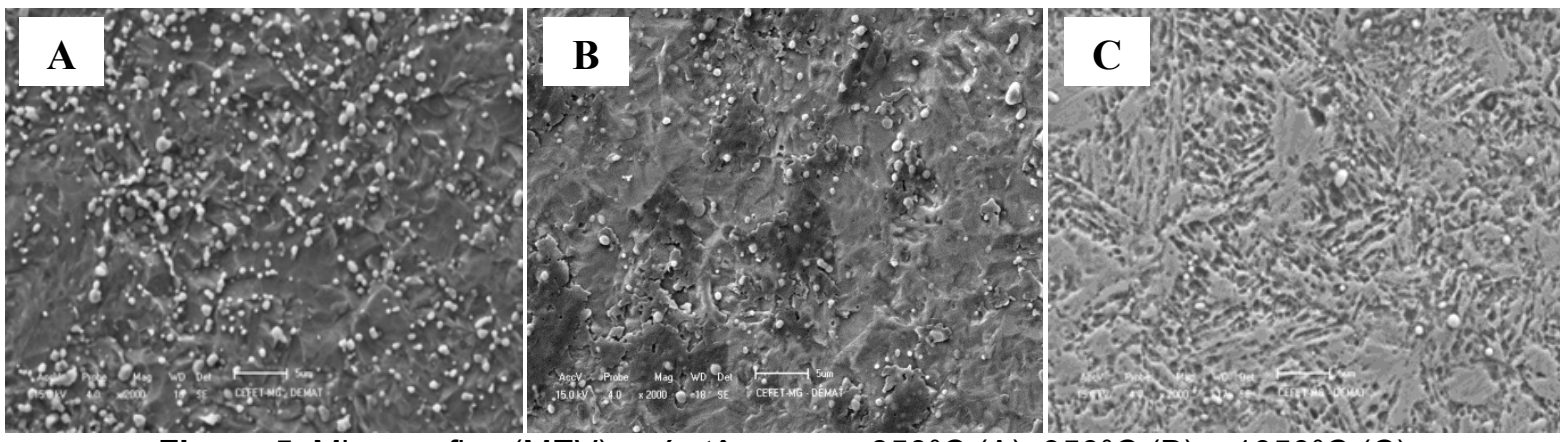

Figura 5. Micrografias (MEV) após têmpera a $850^{\circ} \mathrm{C}(\mathrm{A}), 950^{\circ} \mathrm{C}(\mathrm{B})$ e $1050^{\circ} \mathrm{C}(\mathrm{C})$.

\subsection{Caracterização Mecânica e Microestrutural do Material Temperado e Revenido}

$\mathrm{Na}$ tabela 4 são mostrados os valores médios de dureza para o aço após o tratamento nas seis temperaturas de revenimento estudadas. Na figura 6 é exibido o gráfico referente aos valores de dureza encontrados em função das temperaturas de revenimento.

Tabela 4. Média dos valores de dureza Vickers após o Revenimento

\begin{tabular}{cccc}
\hline & Têmpera $850^{\circ} \mathrm{C}$ & Têmpera $950^{\circ} \mathrm{C}$ & Têmpera $1050^{\circ} \mathrm{C}$ \\
\hline Revenimento a $100^{\circ} \mathrm{C}$ & $446 \pm 13$ & $589 \pm 7$ & $653 \pm 8$ \\
\hline Revenimento a $200^{\circ} \mathrm{C}$ & $464 \pm 5$ & $538 \pm 6$ & $626 \pm 8$ \\
\hline Revenimento a $300^{\circ} \mathrm{C}$ & $443 \pm 4$ & $481 \pm 7$ & $484 \pm 9$ \\
\hline Revenimento a $400^{\circ} \mathrm{C}$ & $407 \pm 6$ & $519 \pm 5$ & $502 \pm 4$ \\
\hline Revenimento a $500^{\circ} \mathrm{C}$ & $447 \pm 9$ & $546 \pm 6$ & $641 \pm 5$ \\
\hline Revenimento a $600^{\circ} \mathrm{C}$ & $317 \pm 11$ & $427 \pm 7$ & $324 \pm 4$ \\
\hline
\end{tabular}

Analisando a figura 6 , verifica-se que para todas as temperaturas de aquecimento na têmpera ocorreu um decréscimo nos valores de dureza após a realização do revenimento com o aumento na temperatura desse tratamento até $300^{\circ} \mathrm{C} / 400^{\circ} \mathrm{C}$. Esse decréscimo foi mais acentuado para o material temperado a $1050^{\circ} \mathrm{C}$, fenômeno que pode ser explicado pelo fato de que com a têmpera a essa temperatura, mais martensita foi formada e, no tratamento subsequente, para essa faixa de temperaturas de revenimento, as principais modificações observadas nas ligas 
ferrosas estão associadas à modificações na estrutura martensítica [14]. Para o aço temperado a $850^{\circ} \mathrm{C}$ e $950^{\circ} \mathrm{C}$, supondo a formação de uma proporção de martensita menor do que na outra condição (a dureza obtida seria proveniente também dos carbonetos primários), as alterações na estrutura martensítica durante 0 revenimento afetariam menos a dureza média da amostra.

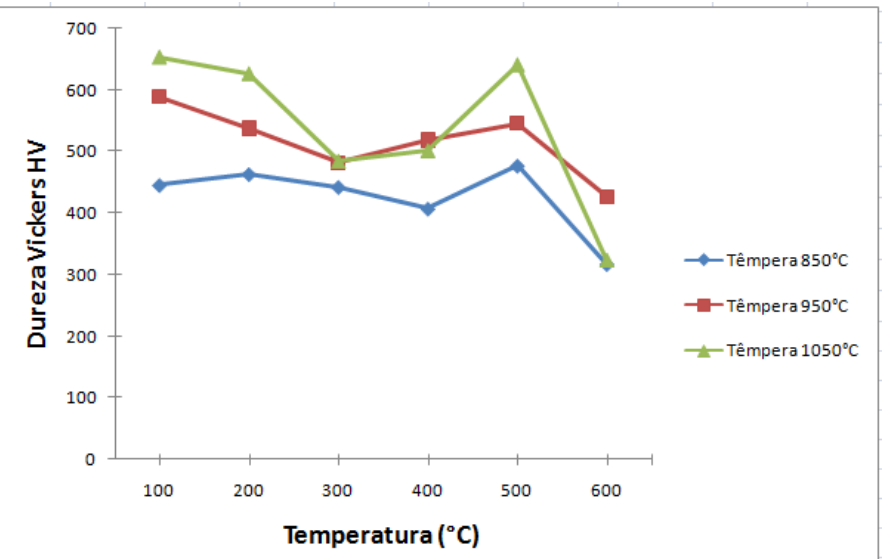

Figura 6. Dureza Vickers em função da temperatura de revenimento nos aços temperados a $850^{\circ} \mathrm{C}$, $950^{\circ} \mathrm{C}$ e $1050^{\circ} \mathrm{C}$.

Após o revenimento a $400^{\circ} \mathrm{C}$, é possível observar a elevação da dureza com a temperatura revenimento, com a presença do pico característico do fenômeno de endurecimento secundário, para as três condições, em uma temperatura de $500^{\circ} \mathrm{C}$. Conforme estudado por [15], a ocorrência do endurecimento secundário na faixa de $500^{\circ} \mathrm{C}$ é associada a uma precipitação fina e homogênea de carbonetos, no caso deste trabalho, possivelmente o $\mathrm{M}_{23} \mathrm{C}_{6}$. Os carbonetos formados no endurecimento secundário são, em geral, duros e finamente dispersos [4], o que contribui para a dureza mais elevada da amostra como um todo ao final do tratamento. Após este pico, a dureza diminuiu com o aumento da temperatura devido possivelmente ao coalescimento dos carbonetos, o que também foi visto por [1].

A diferença de dureza verificada no endurecimento secundário para as três condições iniciais de têmpera deve estar relacionada ao fato de que com o aquecimento a $850^{\circ} \mathrm{C}$ e $950^{\circ} \mathrm{C}$ na têmpera, como já mencionado, menos carbono e demais elementos de liga entraram em solução sólida na austenita. Com isso, a martensita produzida apresentou menos carbono e elementos de liga em solução. Dessa forma, no momento da precipitação de carbonetos no revenimento a $500^{\circ} \mathrm{C}$, possivelmente uma menor proporção de carbonetos deve ter sido formada.

As figuras 7 a 12 correspondem às fotomicrografias (MO e MEV) obtidas para o aço inoxidável aquecido a $850^{\circ} \mathrm{C}, 950^{\circ} \mathrm{C}$ e $1050^{\circ} \mathrm{C}$ e revenido nas temperaturas de $200^{\circ} \mathrm{C}, 400^{\circ} \mathrm{C}$ e $500^{\circ} \mathrm{C}$.

Para o aço temperado a $850^{\circ} \mathrm{C}$ e $950^{\circ} \mathrm{C}$ e revenido, não é possível verificar alterações significativas nas imagens exibidas, tanto em termos de quantidade de carbonetos como em relação à estrutura martensítica. Essa última, aparentemente, torna-se um pouco mais difusa, menos nítida. Já para o aço temperado a $1050^{\circ} \mathrm{C} \mathrm{e}$ revenido, as transformações microestruturais são acentuadas. Considerando a matriz martensítica, com a realização e aumento da temperatura de revenimento, essa estrutura foi se tornando menos nítida, com interfaces menos delimitadas. Em relação aos carbonetos, percebe-se que para temperaturas de $200^{\circ} \mathrm{C}$ e $400^{\circ} \mathrm{C}$, a proporção ainda é reduzida, como acontece com o material temperado. No entanto, 
para $500^{\circ} \mathrm{C}$, verifica-se claramente presença intensa desses precipitados, indicando a ocorrência de endurecimento secundário. A precipitação dos carbonetos foi apontada como responsável pela ocorrência de endurecimento, como aquele visto no gráfico da figura 6 . A degeneração da estrutura martensítica, passando de uma morfologia do tipo deslizada para o tipo maclada, o que é uma característica dos aços de médio carbono, foi verificada por [12].
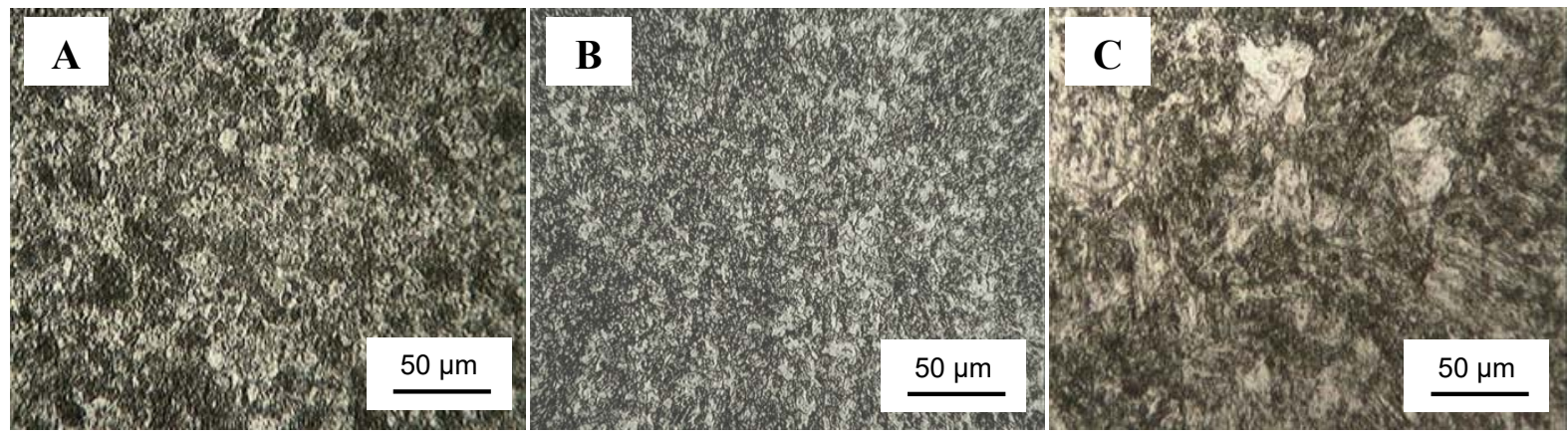

Figura 7. Micrografias (MO) após têmpera a $850^{\circ} \mathrm{C}(\mathrm{A}), 950^{\circ} \mathrm{C}(\mathrm{B})$ e $1050^{\circ} \mathrm{C}(\mathrm{C})$ e revenimento a $200^{\circ} \mathrm{C}$.
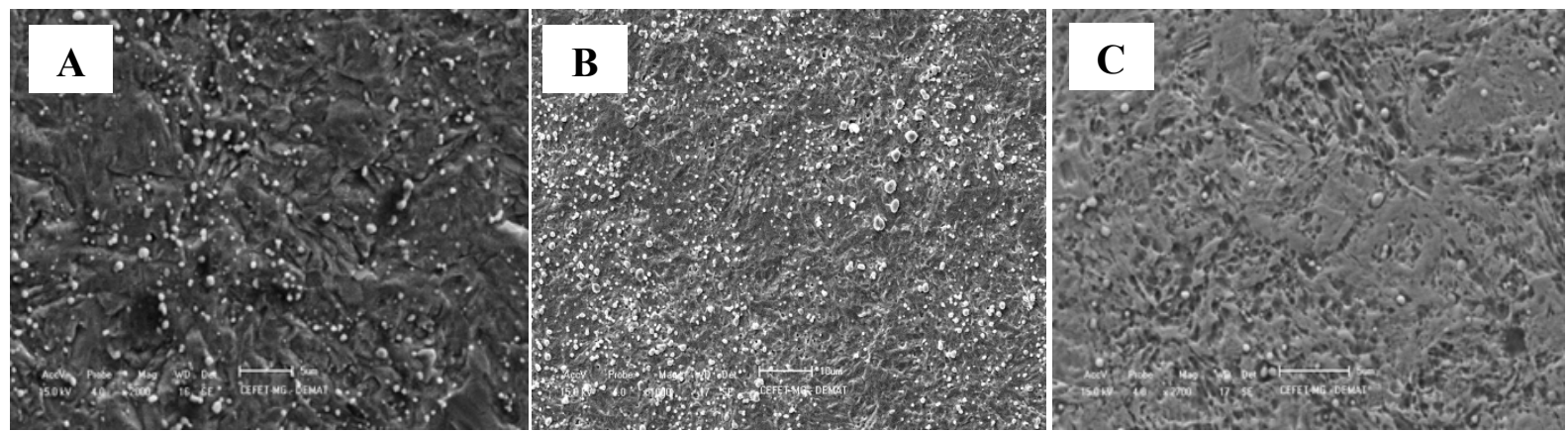

Figura 8. Micrografias (MEV) após têmpera a $850^{\circ} \mathrm{C}(\mathrm{A}), 950^{\circ} \mathrm{C}(\mathrm{B})$ e $1050^{\circ} \mathrm{C}(\mathrm{C})$ e revenimento a $200^{\circ} \mathrm{C}$.
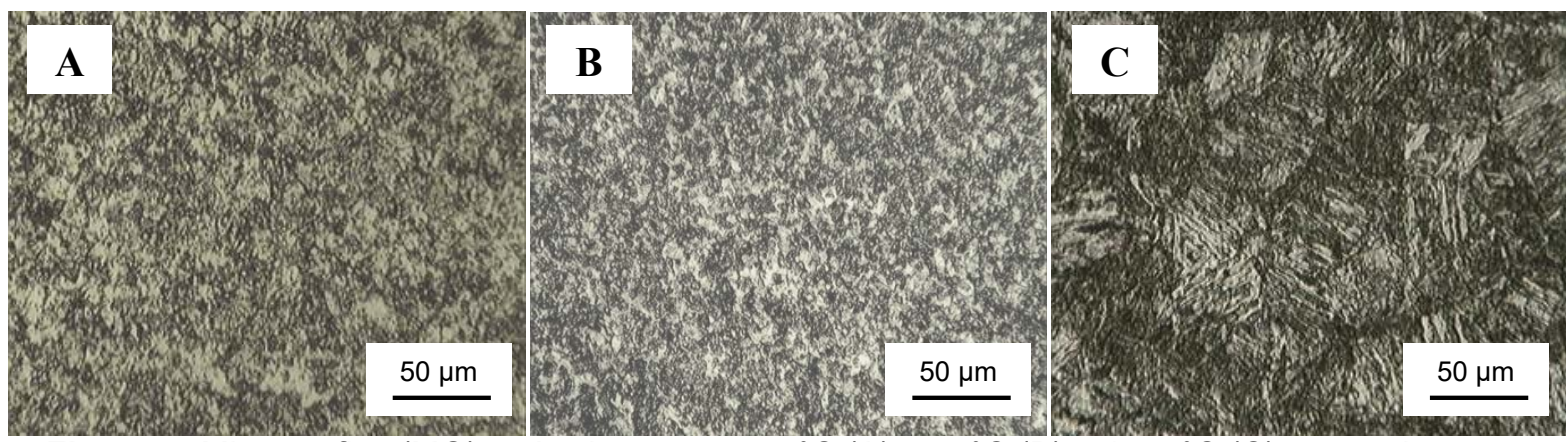

Figura 9. Micrografias (MO) após têmpera a $850^{\circ} \mathrm{C}(\mathrm{A}), 950^{\circ} \mathrm{C}(\mathrm{B})$ e $1050^{\circ} \mathrm{C}(\mathrm{C})$ e revenimento a $400^{\circ} \mathrm{C}$.
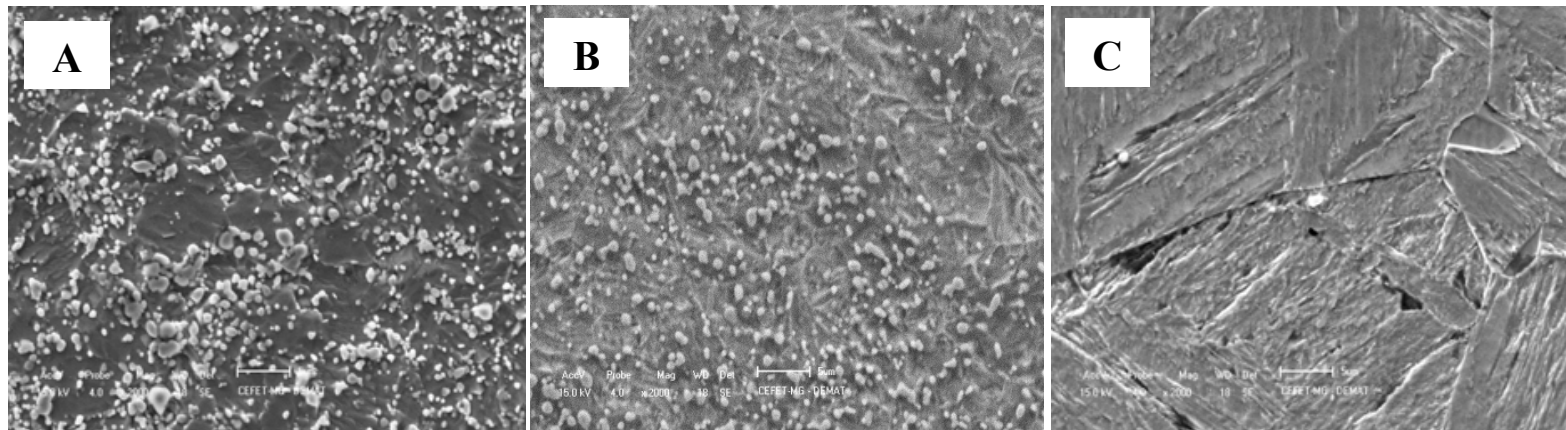

Figura 10. Micrografias (MEV) após têmpera a $850^{\circ} \mathrm{C}(\mathrm{A}), 950^{\circ} \mathrm{C}(\mathrm{B})$ e $1050^{\circ} \mathrm{C}(\mathrm{C})$ e revenimento a $400^{\circ} \mathrm{C}$. 

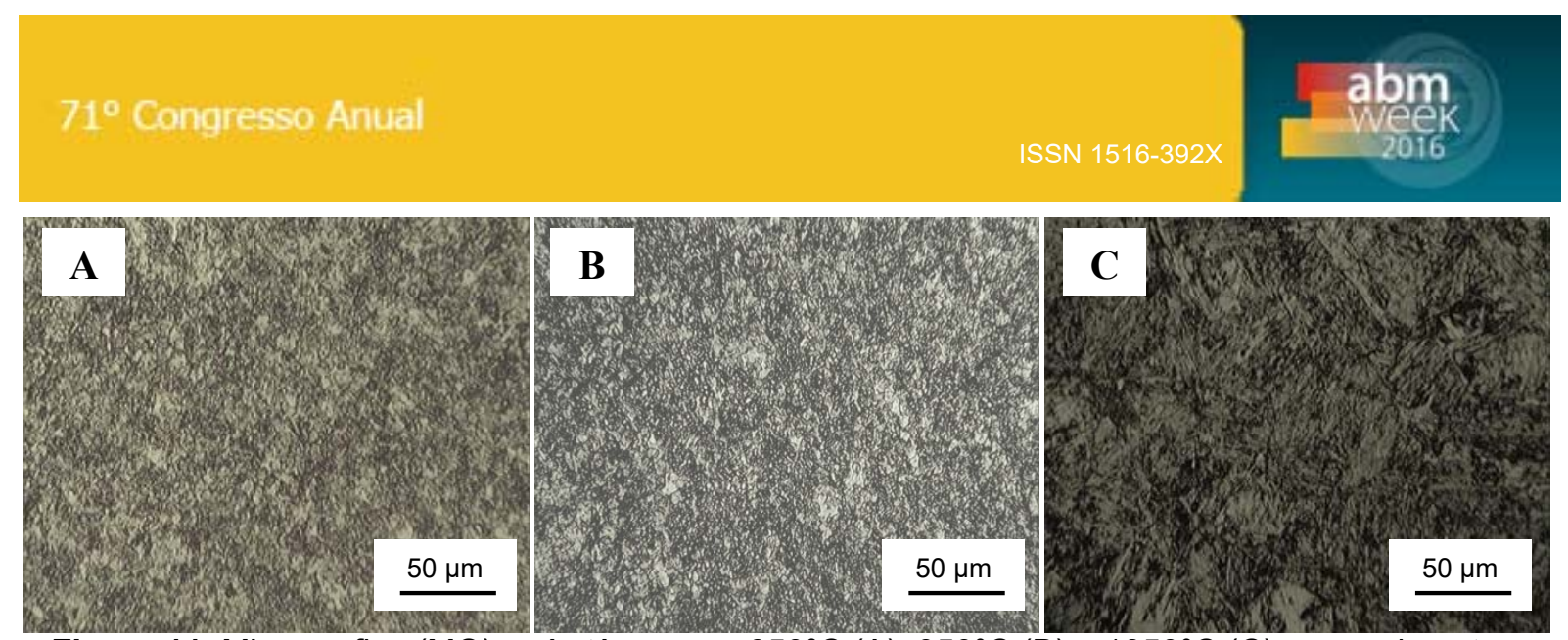

Figura 11. Micrografias (MO) após têmpera a $850^{\circ} \mathrm{C}(\mathrm{A}), 950^{\circ} \mathrm{C}(\mathrm{B})$ e $1050^{\circ} \mathrm{C}(\mathrm{C})$ e revenimento a $500^{\circ} \mathrm{C}$.

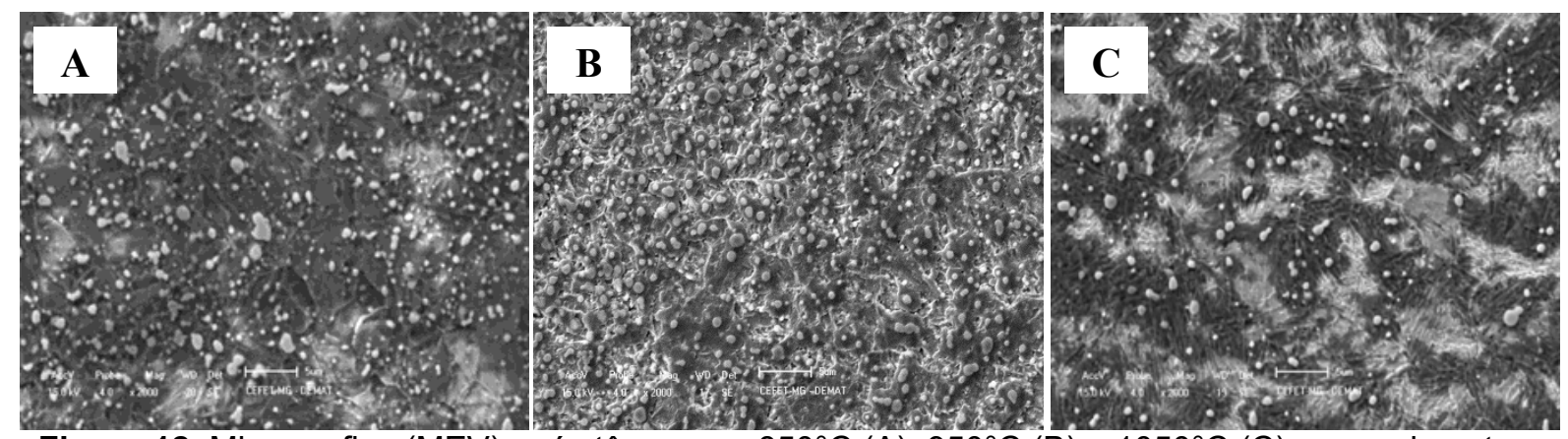

Figura 12. Micrografias (MEV) após têmpera a $850^{\circ} \mathrm{C}(\mathrm{A}), 950^{\circ} \mathrm{C}(\mathrm{B})$ e $1050^{\circ} \mathrm{C}(\mathrm{C})$ e revenimento a $500^{\circ} \mathrm{C}$.

\section{CONCLUSÃO}

O aço inoxidável martensítico $0,45 \% \mathrm{C}-0,39 \% \mathrm{Si}-14,9 \% \mathrm{Cr}-0,65 \% \mathrm{Mo}-0,10 \% \mathrm{~V}$ apresentou valores de dureza mais elevados com o aumento da temperatura de aquecimento na têmpera.

Foi observado que a proporção de carbonetos diminuiu com o aumento da temperatura de aquecimento. Aparentemente, as temperaturas de $850^{\circ} \mathrm{C}$ e de $950^{\circ} \mathrm{C}$ não foram suficientes para dissolver os carbonetos, diferentemente do que ocorreu a $1050^{\circ} \mathrm{C}$, onde a dissolução foi quase completa.

Com a relação com revenimento, foi possível observar o aparecimento do pico de dureza referente à ocorrência de endurecimento secundário a $500^{\circ} \mathrm{C}$ para as todas situações estudadas. A elevação na quantidade de carbonetos precipitados a temperatura de $500^{\circ} \mathrm{C}$, especialmente para o material temperado a $1050^{\circ} \mathrm{C}$, situação na qual o aumento de dureza foi mais acentuado, justifica a ocorrência do fenômeno.

\section{Agradecimentos}

Os autores agradecem à CAPES pela bolsa de mestrado.

\section{REFERÊNCIAS}

1 Calliari I, Zanesco, M, Dabalà, M, Brunelli, K, Ramous, E. Investigation of microstructure and properties of a Ni-Mo martensitic stainless steel. Materials and Design. 2008; 29(1): 246-250.

2 Nasery Isfahany A, Saghafian H, Borhani G. The effect of heat treatment on mechanical properties and corrosion behavior of AISI420 martensitic stainless steel. Journal of Alloys and Compounds. 2011, 509: 3931-3936 
3 Pickering, RB. Physical metallurgical development of stainless steels. Proceedings In Stainless Steels'84. 1984; .2-28.

4 Krauss, $\mathrm{H}$. Steels heat treatment and processing principles. 2a ed. Ohio: ASM International; 1990.

5 Park JY, Park YS. The effects of heat treatments parameters on corrosion resistance and phase transformations of $14 \mathrm{Cr}-3 \mathrm{Mo}$ martensitic stainless steel. Materials Science and Engineering. 2007; 449-451: 1131-1134.

6 Chakraborty, G., Das CR, Albert SK, Bhaduri AK, Paulo VT, Paneerselvam G, Dasgupta A. Study on tempering behaviour of AISI 410 stainless steel. Materials Characterization. 2015, 100: 81-87.

7 Song Y, Cui J, Rong L. Microstructure and mechanical properties of 06Cr13Ni4Mo steel treated by quenching-tempering-partitioning process. Journal of Materials Science \& Technology. 2016, 32: 189-193.

8 Song YY, Li XY, Rong LJ, Ping DH, Yin FX, Li YY. Formation of the reversed austenite during intercritical tempering in a $\mathrm{Fe}-13 \% \mathrm{Cr}-4 \% \mathrm{Ni}-\mathrm{Mo}$ martensitic stainless steel. Materials Letters. 2010, 64: 1411-1414.

9 Bénéteau A, Aeby-Gautier E, Geandier G, Weisbecker P, Redjaimia A, Appolaire B. Tempering of a martensitic stainless steel: Investigation by in situ synchrotron X-ray diffraction. Acta Materialia. 2014, 81: 30-40.

10 Bjarbo A. ;Hatterstrand M. Complex Carbides Growth, Dissolution, and Coarsening in a Modified 12 Pct Chromium Steel-An Experimental and Theoretical Study. Metallurgical and Materials Transactions. 2001; 32(1): 19-27.

11 Lo KH, Shek CH, Lai JKL. Recent developments in stainless steels. Materials Science and Engineering. 2009; 65(4-6): 39-104.

12 Pinedo CE. Tratamento Térmico e Superficial do Aço Inoxidável Martensítico AISI 420 destinado a Moldes para Injeção de Polímeros: Parte I - Tratamento Térmico". In: Anais do 20 Encontro da Cadeia de Ferramentas, Moldes e Matrizes - ABM. São Paulo: 2004. 281-292.

13 Barlow LD. Effect of the austenitising heat treatment on the microstructure and hardness of martensitic stainless steel AISI 420. Journal of Materials Engineering and Performance. 2012; 21(7): 1327-1336.

14 Chiaverini V. Aços e ferros fundidos. 7a ed. São Paulo: Associação Brasileira de Metalurgia e Materiais - ABM, 2005.

15 Speich G R, Leslie WC. Tempering of Steel. Metallurgical Transactions. 1972; 3: 10431054. 